\title{
REVIEWS
}

\section{Familiar drugs may prevent cancer}

\author{
R A Sharma, A J Gescher, K J O’Byrne, W P Steward
}

Oncology Department, University of Leicester, Leicester Royal Infirmary, Leicester LE1 5WW, UK

R A Sharma

K J O'Byrne

W P Steward

MRC Toxicology Unit, University of Leicester A J Gescher

Correspondence to:

Dr Sharma

ras20@le.ac.uk

Submitted 10 October 2000 Accepted 15 February 2001

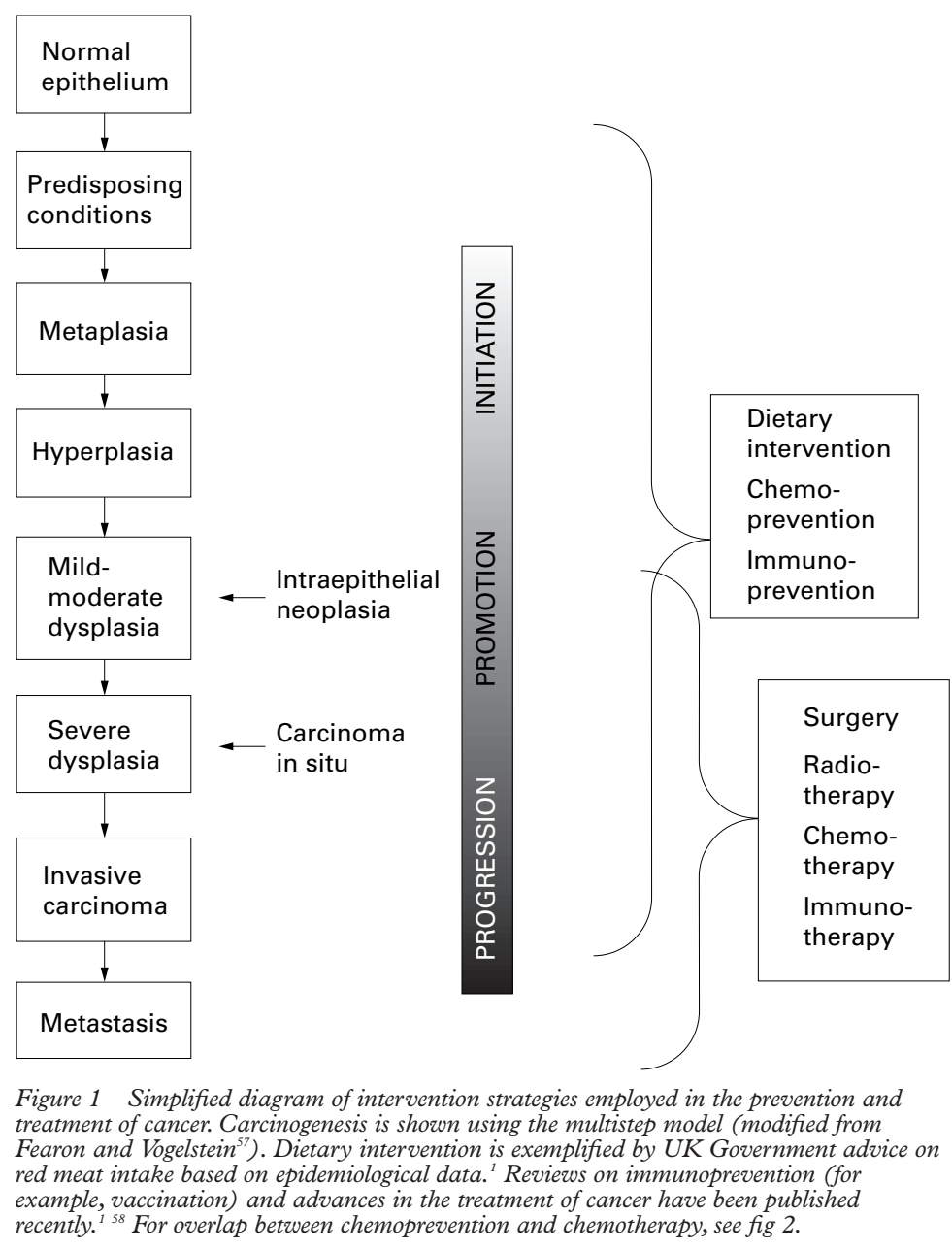
have proved efficacious in the tertiary chemoprevention of cancers of the breast and head/neck. Epidemiological evidence also exists in favour of aspirin, nonsteroidal anti-inflammatory drugs, and angiotensin converting enzyme inhibitors preventing certain cancers. Phytochemicals may represent less toxic alternatives to these agents. Although some of these drugs are available without prescription and most are not yet licensed for use in cancer chemoprevention, physicians and students of medicine should be aware of this accumulating evidence base. Practitioners should be amenable to patient referral to discuss complex issues such as risk estimation or potential benefit from intervention.

(Postgrad Med f 2001;77:492-497)

Keywords: cancer chemoprevention; tamoxifen; folate; retinoids; cyclo-oxygenase

Cancer incidence and mortality continues to increase, and it has now overtaken heart disease as the commonest cause of death in Britain and Ireland. ${ }^{1}$ Although tamoxifen may have attenuated the rising mortality rates from breast cancer, ${ }^{2}$ chemotherapy has displayed a disappointing lack of impact on the prognosis from solid malignancies in general. Alternative strategies (see fig 1) have developed since the "war on cancer" was first announced by US President Nixon in 1971. One involves pharmacological intervention to arrest, inhibit or reverse carcinogenesis, and is termed cancer chemoprevention. ${ }^{3}$ Its definitions are shown in fig 2 .

Two drugs have already been licensed in the USA for use in cancer chemoprevention (see below) and results of large European clinical trials are eagerly awaited. ${ }^{4}$ Despite the absence of licensed drugs in countries such as Britain, physicians are often asked questions about cancer prevention by patients' relatives and "high risk" individuals, not least because of the frequently held fears evoked by this common disease and its media coverage. Such questions pertain to some of the drugs in common clinical usage for other diseases. Unlike the prevention of cancer, primary and secondary prevention are well established in other diseases such as dental caries, heart attacks, and stroke, and play a prominent part in medical education. It should be noted that any physician directly or indirectly involved with cancer screening is increasingly likely to encounter such questions, since many of the tests used will detect high risk patients with premalignant disease. ${ }^{4}$

The aim of this review is to inform practising physicians of positive large scale chemoprevention trials, and why these drugs may prevent cancer. From our experience, patients tend to ask about specific drugs, and we will therefore 


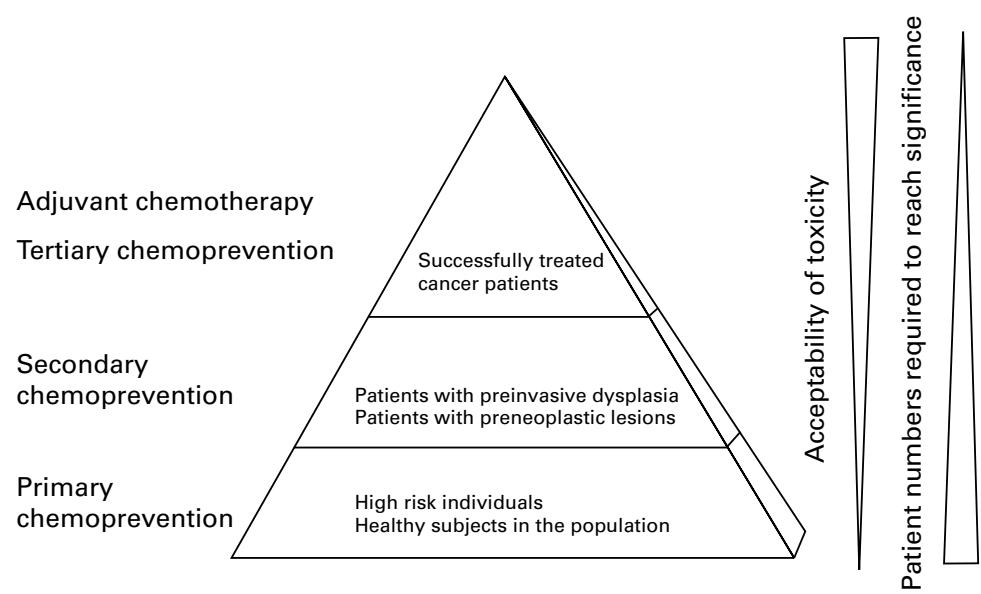

Figure 2 The levels of cancer chemoprevention, as defined by subject group (modified from Gescher et $a^{49}$ and De Flora et $a l^{59}$. Drug toxicity is least acceptable in primary chemoprevention, where large numbers of subjects are required for results to reach statistical significance. ${ }^{60}$

divide the text by agent rather than by disease. For organ based reviews of cancer chemoprevention, the reader is advised to read the key references shown in box 2 .

\section{Tamoxifen}

Successful chemopreventive agents may be developed from their proven role in palliative or adjuvant chemotherapy. An example is the oestrogen analogue tamoxifen, which was initially found to improve survival in patients with metastatic breast cancer, ${ }^{5}$ and subsequently found to decrease the incidence of tumours in the contralateral breast after surgery. ${ }^{6}$ Forty per cent of newly diagnosed female cancers in the USA arise in tissues responsive to hormones, ${ }^{7}$ and it is known that the incidence of endometrial, ovarian, and breast cancers rises in an age dependent fashion similar to other cancers only until the menopause, after which time there is a distinct slowing of the rate of rise. ${ }^{8}$ Epidemiological evidence for the role of oestrogen as a primary stimulant of breast cell proliferation is supported by preclinical and clinical studies, ${ }^{78}$ and unlike the response in the uterus, the proliferation of breast cells is probably augmented by progestogens. ${ }^{7}$ Receptor antagonism is therefore an important mechanism of intervention during breast carcinogenesis, and the demonstration of the occurrence of the oestrogen receptor- $\beta$ in prostate, colon, and ovary offers similar potential for these tissues. ${ }^{9}$

Significant controversy exists between North America and Europe regarding the proved clinical efficacy of the two antioestrogenic agents, tamoxifen and raloxifene, both synthesised more than 20 years ago, well before the cloning and mechanistic elucidation of oestrogen receptors. The Breast Cancer Prevention Trial (BCPT) study in the US involved 13388 women of "relatively high risk" (that is, with a substantially greater than $1.66 \%$ chance of developing breast cancer within five years), but free of detectable invasive breast cancer at study recruitment. ${ }^{10}$ Risk was determined using a mathematical model previously published, ${ }^{11}$ and included factors such as age (any woman 60 or more years old was eligible), benign breast disease, nulliparity, and family history. Tamoxifen reduced relative risk for subsequent development of breast cancer in the treated group as a whole by $45 \%$, and may also have prevented the progression of established preneoplastic lesions. These results led the Food and Drug Administration to approve the use of tamoxifen $(20 \mathrm{mg} /$ day $)$ by women deemed at increased risk of developing breast cancer, albeit with consideration of its toxicities. Tamoxifen causes hot flushes, vaginal bleeding or discharge, fluid retention and amenorrhoea, increases risk for venous thromboembolic events ${ }^{10}$ and can cause endometrial hyperplasia, dysplasia, and carcinoma. ${ }^{12}$ Extrapolating from data on its effect in the adjuvant chemotherapy setting, one might speculate that tamoxifen continues to reduce the incidence of primary breast cancer for at least five years after treatment stops. ${ }^{2}$ However, caution is advised since no reduction in mortality has yet been demonstrated in the BCPT study, perhaps because this drug may prevent only oestrogen receptor positive tumours, ${ }^{13}$ which may respond to hormonal manipulation even once carcinoma is established.

Results favouring the prevention of breast cancer have also been published in a trial of raloxifene in postmenopausal women with known osteoporosis, but not considered at increased risk of breast cancer. ${ }^{14} \mathrm{~A}$ larger breast cancer prevention trial of raloxifene is ongoing, enrolling 20000 women and due for publication in 2006. Raloxifene, licensed in most countries only for the chemoprevention of osteoporosis, is generally better tolerated than tamoxifen. It may also cause hot flushes and peripheral oedema, and does increase risk for thromboembolism, ${ }^{15}$ but may not possess the endometrial stimulatory properties of tamoxifen. ${ }^{12} 14$

In contrast to the BCPT study, two smaller European trials of tamoxifen in healthy women, with lower average risk factors, have not demonstrated any protective effects. ${ }^{16}{ }^{17}$ In the Italian study, ${ }^{16}$ post-hysterectomy patients were included, and the British study ${ }^{17}$ allowed patients to continue supplemental oestrogen therapy; the mean age of participants for both trials was lower than the BCPT study. Consequently, in Europe the results of the International Breast Cancer Intervention study (IBIS) are awaited, in which more than 4000 women with at least a twofold increased risk of developing breast cancer have been recruited.

The controversy regarding the benefit of agents such as tamoxifen in preventing breast cancer in the US compared with Europe illustrates the importance of subject selection in large scale chemoprevention trials. It is feasible that high risk subgroups, perhaps with particular molecular defects (see below) or a certain receptor status in preneoplastic lesions, must be studied for statistical significance to be demonstrated. Indeed such individuals may have the most favourable benefit-toxicity ratios. 


\section{Box 1: Key points}

- There is increasing epidemiological evidence that certain drugs may decrease the incidence of cancer.

- Two drugs have been licensed in the USA for the chemoprevention of breast and colorectal cancers in selected high risk individuals.

- Folate and retinol have been shown to decrease the incidence of colorectal and skin squamous cell cancers respectively in large scale intervention trials.

- Aspirin, NSAIDs, and ACEIs may also reduce cancer incidence, as may certain phytochemicals.

- Practitioners should be amenable to referral of individuals in whom there is objective evidence of high risk that they may develop certain cancers.

\section{Aspirin and NSAIDs}

Retrospective epidemiological studies suggest a decreased incidence of cancers of the oesophagus, stomach, colon, and rectum in regular users of non-steroidal anti-inflammatory drugs (NSAIDs). ${ }^{18}$ The most convincing evidence exists for regular usage of aspirin, which may reduce the incidence of colorectal cancer by up to $50 \%,{ }^{19}{ }^{20}$ although there may be a delay of approximately one decade before the benefits of daily usage are seen. ${ }^{21}$ Colorectal adenomas have been regarded as the quintessential precursor lesions of cancer since the $1970 \mathrm{~s},{ }^{22}$ and are present in a third of the general population by the age of 50 years and approximately half the population by the age of 70 years. ${ }^{23}$ Mutations in the $A P C$ gene, first described in the inherited syndrome of familial adenomatous polyposis (FAP), are found in $80 \%$ of all colorectal adenomas and carcinomas. ${ }^{24} \mathrm{Al}-$ though FAP accounts for only $0.5 \%$ of all colorectal cancers, this disease may therefore represent a useful model of the more common sporadic form of this cancer.

In individuals with FAP, the presence of the $A P C$ gene defect confers a nearly $100 \%$ lifetime risk of developing colorectal cancer. ${ }^{24}$ At present such individuals are advised to undergo regular colonoscopy with or without colectomy. It has been known for many years that aspirin and NSAIDs, such as sulindac, can cause regression of FAP polyps, although adenomas do recur and regrow when treatment is curtailed. ${ }^{25}$ The postulated mechanism is their ability to inhibit the cyclo-oxygenase (COX) enzyme involved in prostaglandin synthesis. COX consists of two isoforms, and aspirin's irreversible acetylation of COX-1 is thought to account predominantly for its gastrointestinal toxicity. ${ }^{26}$ Highly selective inhibitors of COX-2, such as celecoxib, have therefore been developed. COX-2 has been implicated in the pathogenesis of human cancers of the colorectum, breast, head/neck, lung, pancreas, stomach, and prostate. ${ }^{26}$ Celecoxib, originally licensed in Europe and

\section{Box 2: Five key references}

1. Chemoprevention Working Group. Prevention of cancer in the next millennium: report of the chemoprevention working group to the American Association for Cancer Research. Cancer Res 1999;59:4743-58.

2. Lippman SM, Lee JJ, Sabichi AL. Cancer chemoprevention: progress and promise. $\mathcal{F}$ Natl Cancer Inst 1998;90:1514-28.

3. Kelloff JG, Crowell JA, Hawk ET, et al. Strategy and planning for chemopreventive drug development: clinical development plans II. $\mathcal{F}$ Cell Biochem 1996;26S:54-71.

4. Sharma RA, Manson MM, Gescher A, et al. Colorectal cancer chemoprevention: biochemical targets and clinical development of promising agents. Eur F Cancer 2001;37:12-22.

5. Sporn MB, Suh N. Chemoprevention of cancer. Carcinogenesis 2000;21:525-30.

North America for the treatment of arthritis, was recently approved by the US Food and Drug Administration as an adjunct to usual care for patients with FAP. This decision was based on the results of a double blind, placebo controlled trial in 83 patients with FAP, which demonstrated that $400 \mathrm{mg}$ of celecoxib twice daily for six months resulted in polyp incidence $28 \%$ lower than placebo. ${ }^{27}$ Other "surrogate" biomarkers, such as prostaglandin synthesis or COX-2 expression, were not measured. Such biomarkers allow prediction of effects on cancer mortality based on scientific hypotheses, for example colorectal cancer develops in adenomas, ${ }^{22} \mathrm{COX}-2$ levels in adenomas represent carcinogenic progression, ${ }^{26}$ and suppression of COX-2 levels may represent efficacy of intervention. ${ }^{4}$

The long term safety of selective COX-2 inhibitors such as celecoxib remains unknown, but early indications are that their side effect profile is similar to that of traditional NSAIDs, although peptic ulceration appears to be less likely than for the older agents. ${ }^{28}$ These agents are likely to maintain selectivity for COX-2 over COX-1 at the dose range used in the published study. ${ }^{27}$ Irreversible inhibition of COX-1 by aspirin accounts for its antiplatelet effect since these cells do not possess nuclei and are

Box 3: Useful websites for monitoring chemoprevention trials ongoing

- http://clinicaltrials.gov/

- http://cancernet.nci.nih.gov/cgi-bin/ srchcgi.exe

- http://www.cdc.gov/cancer/index.htm

- http://iarc.fr/pageroot/UNITS/ CHP.HTM

- http://cancerindex.org/clinks4t.htm 


\section{Questions (see answers on p 496)}

1. Which two drugs have been licensed by the US Food and Drug Administration for the chemoprevention of breast and colorectal cancers respectively; in which highly selected individuals?

2. According to the Nurses' Health Study, how much folate must be taken as a supplement for how long in order to decrease the incidence of colorectal cancer?

3. (A) In the pathogenesis of which human cancers has COX-2 been implicated? (B) Which drugs inhibit the COX enzyme?

4. Why are biomarkers useful in cancer chemoprevention trials?

5. (A) In what disease does differentiation therapy with all-trans retinoic acid lead to complete remission in the vast majority of patients? (B) Which skin cancer might retinol prevent?

6. In which dietary components are the following putative cancer chemopreventives found: EGCG, curcumin, genistein, resveratrol?

unable to resynthesise the enzyme. A low dose of aspirin is therefore equally efficacious in cardiovascular chemoprevention as larger doses, and lasts for the duration of each platelet life in vivo. This is fortunate since the likelihood of peptic ulceration, haemorrhage, and renal impairment do increase with dose. ${ }^{29}$ In contrast, aspirin inhibits COX-2 by competitive inhibition and one might expect that if this is the mechanism of its cancer chemopreventive efficacy, higher doses should be more beneficial. One epidemiological study suggests that this may be the case, ${ }^{30}$ but measurement of prostaglandin levels in a target tissue such as colon epithelium has suggested that a dose of aspirin as low as $81 \mathrm{mg} /$ day may be sufficient for cancer chemoprevention. ${ }^{31}$ The duration of use also appears critical, and there may be a "latency" period of a decade or more before statistically significant trends are seen in colorectal cancer incidence. It should also be noted that, unlike selective COX-2 inhibitors, aspirin exhibits other biological actions such as inhibition of peroxidase enzyme activity ${ }^{32}$ and induction of apoptosis in cancer cells. ${ }^{27}$ We conclude that although only one selective COX-2 inhibitor has been licensed for cancer chemoprevention in FAP patients in the USA, the more toxic drug aspirin may have more diverse efficacy in preventing sporadic cancer.

\section{Folate}

Folate supplementation is well established in the chemoprevention of fetal neural tube defects during pregnancy. Consequently, many foods are fortified with folic acid for its potentially beneficial effects. Large amounts of folate in the diet also appear to be protective against the development of colorectal adenomas. ${ }^{33}$
Folate is central to methyl group metabolism, and as such may influence both methylation of DNA and the available nucleotide pool for DNA replication and repair. ${ }^{34}$ DNA hypomethylation is an early step in colon carcinogenesis. ${ }^{35}$ Vitamin $B_{12}$ is a cofactor in this pathway, and the val/val polymorphism of the methylenetetrahydrofolate reductase (MTHFR) gene may also influence the association between folate intake and the development of carcinoma from adenoma. $^{36} 37$

The degree of benefit from taking folate supplements may be greater than that from its consumption in the diet. The Nurses' Health Study began in 1976 and followed 121700 married, registered female nurses of ages 30-55 years prospectively by questionnaire. In one subgroup, supplementation with folate was protective against colorectal cancer, with the greatest risk reduction among women taking daily doses of more than $400 \mu \mathrm{g}$ folate; however, this reduction became statistically significant only after 15 years of use. ${ }^{38}$ It is also becoming apparent that the protective role of folate supplementation may be greatest for those genetically predisposed to colorectal cancer, and that the benefit conferred by MTHFR genotype may be offset by a methyl deficient diet. ${ }^{37}$

\section{Retinoids}

Like folate, retinol (vitamin A) is available in the diet, particularly from green leafy vegetables, liver, eggs, and milk. Retinol is the precursor of all physiologically occurring retinoids, and is required for normal vision and reproduction. The oxidation products of retinol are essential for the maintenance of normal epithelial differentiation (reviewed in Hansen $e t$ $\left.a b^{39}\right)$.

It has been hypothesised that retinoids, at optimal or supraphysiological levels, inhibit the development of epithelial carcinogenesis. This activity is utilised in acute promyelocytic leukaemia, in which treatment with all-trans retinoic acid leads to complete remission in up to $95 \%$ of patients. $^{40}$ In the Skin Cancer Prevention-Actinic Keratosis trial, 25000 IU of retinol was taken daily and primary prevention of squamous and basal cell carcinomas of the skin were the two endpoints measured. ${ }^{41}$ The trial involved 2297 subjects deemed to be at moderate risk, and the treatment was found to prevent squamous cell carcinoma significantly. A drawback of this study is the fact that increasing dietary ingestion of retinol is unlikely to deliver more retinol to skin; it merely leads to an accumulation of retinyl esters in liver tissue. It has therefore been proposed that direct administration of retinoids to target tissues may be more effective chemoprevention than oral supplementation. ${ }^{39}$

It is vital that any agent under consideration for chemoprevention in healthy high risk individuals over prolonged periods of time should not cause more harm than benefit. ${ }^{4}$ Although the retinoids, isotretinoin ${ }^{42}$ and retinol palmitate, ${ }^{43}$ have been demonstrated to prevent second primary cancers in patients with malignancies of the lung and head/neck, 


\section{Answers}

1. Tamoxifen has been licensed for the primary chemoprevention of breast cancer in high risk individuals after consideration of its toxicities. Risk can be determined mathematically, using factors such as age, benign breast disease, nulliparity, and family history. Celecoxib, the selective COX-2 inhibitor, has been licensed as an adjunct to standard treatment of patients with familial adenomatous polyposis. This represents secondary chemoprevention (see fig 2).

2. In one subgroup of this large trial, supplementation with folate was protective against colorectal cancer, reaching signficance in women taking daily doses of more than $400 \mu \mathrm{g}$ folate for 15 years.

3. (A) COX-2 has been implicated in the pathogenesis of human cancers of the colorectum, breast, head/neck, lung, pancreas, stomach, and prostate. (B) Aspirin, NSAIDs, selective COX-2 inhibitors, and certain phytochemicals (for example curcumin, resveratrol) inhibit the COX enzyme.

4. If cancer mortality acts as the only endpoint, chemoprevention trials must study time periods of 5-15 years in order to reach significance, with no indication of beneficial or detrimental effects. "Surrogate" biomarkers allow prediction of the efficacy of intervention based on scientific hypotheses of carcinogenesis.

5. (A) Acute promyelocytic leukaemia. (B) Squamous cell carcinoma of the skin.

6. They are found in tea, the spice turmeric, soya, and wine respectively.

compliance is often problematic on account of toxicity. Similarly the synthetic retinoid, fenretinide, significantly decreased the risk of breast cancer in premenopausal women in a tertiary chemoprevention study (see fig 2), but night blindness and erythema proved prohibitive at higher doses. ${ }^{44}$ Newer retinoids that selectively bind to retinoid $\mathrm{X}$ receptors appear highly chemopreventive in preclinical models of epidermal and mammary carcinogenesis, and do not possess the toxicity/teratogenicity profile of the classical retinoids. ${ }^{9}$

\section{Others}

Treatment of hypertensive patients with captopril, an angiotensin-I converting enzyme inhibitor (ACEI), is associated with a reduced risk of developing malignancy, particularly lung and breast cancers. ${ }^{45}$ This may relate to the ability of ACEIs to inhibit angiogenesis, the formation of new blood vessels vital to growth of cancers beyond $1-2 \mathrm{~mm}^{3} .^{46}$ As well as inhibiting chemotaxis of capillary cells, captopril is a free sulfhydryl donor which can lead to the generation of antiangiogenic compounds in vitro. ${ }^{47}$ Captopril also inhibits matrix metalloproteinase activity, integral to the neovascularisation process. ${ }^{48}$

Finally, certain phytochemicals offer a minimally toxic form of intervention during carcinogenesis with similar mechanisms to those described above. ${ }^{49}$ An example is provided by curcumin, a potent antioxidant derived from the spice turmeric. This compound appears innocuous in doses up to $8 \mathrm{~g} / \mathrm{day},{ }^{50}$ yet possesses biological activity in micromolar concentrations very similar to that of aspirin. ${ }^{5152}$ In addition, it appears to inhibit other processes linked to carcinogenesis, such as lipid peroxidation $^{53}$ and angiogenesis. ${ }^{54}$ Other such putative chemopreventive agents include epigallocatechin gallate (EGCG) in green and black tea, the isoflavone genistein found in soya, resveratrol from wine, and micronutrients such as selenium and vitamin $\mathrm{D}_{3}{ }^{55}{ }^{56}$ Both curcumin and EGCG have been shown to affect processes pivotal to cell signalling, such as kinases, cell cycle regulatory proteins, and downstream elements of cellular signalling cascades crucial for cell proliferation (reviewed in Gescher $\left.e t a l^{49}\right)$. A convergence is thus developing between the targets identified for cancer chemopreventive agents and those for chemotherapeutic drugs. It is conceivable that modification of these targets may prove more efficacious in intervention when fewer cellular components are malfunctioning (chemoprevention) than treatment when dysregulation of many pathways is already established (chemotherapy).

\section{Conclusions}

Physicians should be aware of the potential cancer chemopreventive properties of commonly used drugs. Tamoxifen was found to reduce breast cancer development in high risk women in one large controlled intervention study, and the results of a similar study in Europe are awaited. Consideration of its toxicities must be weighed up against the cancer risk for each individual. Raloxifene, already used in the chemoprevention of osteoporosis, may offer a less toxic alternative to tamoxifen. A large prospective intervention study has found that folate supplementation may decrease the incidence of colorectal cancer after 15 years of daily use. NSAIDs and celecoxib have been shown to cause regression of adenomas, considered the premalignant lesions in this disease. Retrospective epidemiological surveys have suggested that aspirin may significantly reduce the incidence of colorectal cancer after at least nine years of daily usage. As demonstrated by studies of celecoxib and folate, consideration of risk ratios and genetic predisposition is increasingly important in recruitment and subset analysis of chemoprevention trials. Retinoids have been shown to be efficacious in the primary prevention of skin squamous cell carcinoma, and the tertiary chemoprevention of cancers of breast and head/ neck, but toxicity has proved limiting. ACEIs and phytochemicals may also prevent certain cancers, and the latter may represent less toxic 
alternatives to conventional drugs. There are complex issues in assessing one's risk of developing cancer and the potential benefit from intervention; practitioners should be amenable to patient referral should individuals wish to discuss these issues with specialist oncologists.

The authors are supported by the UK Medical Research Council, a research fellowship from the University Hospitals of Leicester and the Institute of Cancer Studies, Leicestershire and Rutland.

1 Tattersall MHN, Thomas H. Recent advances: oncology. BMF 1999;318:445-8

2 Jordan VC. Tamoxifen: a personal retrospective. Lancet Oncol 2000;1:43-9.

3 Sporn MB, Newton DL. Chemoprevention of cancer with retinoids. Fed Proc 1979;38:2528-34.

4 Sharma RA, Manson MM, Gescher A, et al. Colorectal cancer chemoprevention: biochemical targets and clinical development of promising agents. Eur f Cancer 2001;37:125 Cole

5 Cole MP, Jones CT, Todd ID. A new anti-oestrogenic agent in late breast cancer. Br $\mathcal{F}$ Cancer 1971;25:270-5.

6 Cuzick J, Baum M. Tamoxifen and contralateral breast cancer. Lancet 1985;ii:282.

7 Henderson BE, Bernstein L, Ross R. Etiology of cancer: Henderson BE, Bernstein L, Ross R. Etiology of cancer:
hormonal factors. In: DeVita VT, Hellman S, Rosenberg hormonal factors. In: DeVita VT, Hellman S, Rosenberg RA, eds. Cancer: principles and practice of oncology

8 Henderson BE, Ross RK, Pike MC. Endogenous hormones as a major factor in human cancer. Cancer Res 1982;42: 3232-9

9 Sporn MB, Suh N. Chemoprevention of cancer. Carcinogenesis 2000;21:525-30

10 Fisher B, Costantino JP, Wickerham DL, et al. Tamoxifen for prevention of breast cancer: report of the National Surgical Adjuvant Breast and Bowel Project P-1 Study. 7 Nat Cancer Inst 1998;90:1371-88.

11 Gail MH, Brinton LA, Byar DP, et al. Projecting individualized probablities of developing breast cancer for white females who are being examined annually. $\mathcal{F}$ Natl Cancer Inst 1989;81:1879-86.

12 Bergman L, Beelen MLR, Gallee MPW, et al. Risk and prognosis of endometrial cancer after tamoxifen for breast prognosis of endometrial cancer
cancer. Lancet 2000;356:881-7.

13 Early Breast Cancer Trialists Collaborative Group. Tamoxifen for early breast cancer: an overview of the Tamoxifen for early breast cancer: an overy

14 Cummings SR, Eckert S, Krueger KA, et al. The effect of raloxifene on risk of breast cancer in postmenopausa women. $\mathcal{F} A M A$ 1999;281:2189-97.

15 Hulley SB, Grady D, Bush T, et al. Randomized trial of estrogen plus progestin for secondary prevention of
coronary heart disease in postmenopusal women. $7 A M A$ 1998;280:605-13.

16 Veronesi U, Maisonneuve P, Costa A, et al. Prevention of breast cancer with tamoxifen. Lancet 1998;352:93-7.

17 Powles T, Eeles R, Ashley S, et al. Interim analysis of the incidence of breast cancer in the Royal Marsden Hospital tamoxifen randomised chemoprevention. Lancet 1998;352: tamoxife

18 Langman MJS, Cheng KK, Gilman EA, et al. Effect of antiinflammatory drugs on overall risk of common cancer: a inflammatory drugs on overall risk of common cancer: a BMf 2000;320:1642-6.

19 Giovannucci E, Rimm EB, Stampfer MJ, et al. Aspirin use and the risk for colorectal cancer and adenoma in male health professionals. Ann Intern Med 1994;121:241-6.

20 Thun MJ, Namboodiri MM, Heath CW Jr. Aspirin use and reduced risk of fatal colon cancer. $N$ Engl f Med 1991;325: 1593-6.

21 Collet J-P, Sharpe C, Belzile E, et al. Colorectal cancer prevention by non-steroidal anti-inflammatory drugs: effects of dosage and timing. Br f Cancer 1999;81:62-8.

22 Muto T, Bussey HJR, Morson BC. The evolution of cancer of the colon and rectum. Cancer 1975;36:2251-70.

23 Williams AR, Balasoriya BA, Day DW. Polyps and cancer of the large bowel: a necropsy study in Liverpool. Gut 1982;23: 835-42.

24 Goss KH, Groden J. Biology of the adenomatous polyposis coli tumor suppressor. F Clin Oncol 2000;18:1967-79.

25 Giardiello FM, Hamilton SR, Krush AJ, et al. Treatment of colonic and rectal adenomas with sulindac in familial adenomatous polyposis. N Engl f Med 1993;328:1313-16.

26 Prescott SM, Fitzpatrick FA. Cyclooxygenase-2 and carcinogenesis. Biochim Biophys Acta 2000;1470:M68-78.

27 Steinbach G, Lynch PM, Phillips RKS, et al. The effect of celecoxib, a cyclooxygenase-2 inhibitor, in familial adenomatous polyposis. N Engl f Med 2000;342:1946-52

28 Are rofecoxib and celecoxib safer NSAIDs? Drug Ther Bulletin 2000;38:81-6.

29 Roderick PJ, Wilkes HC, Meade TW. The gastrointestinal toxicity of aspirin - an overview of randomised controlled trials. Br f Clin Pharmacol 1993;35:219-26.
30 Rodriguez LAC, Huerta-Alvarez C. Reduced incidence of colorectal adenoma among long-term users of nonsteroidal antiinflammatory drugs: a pooled analysis of published antiinflammatory drugs: a pooled analysis of published
studies and a new population-based study. Epidemiology

31 Ruffin MT, Krishnan K, Rock CL, et al. Suppression of human colorectal mucosal prostaglandins: determining the lowest effective aspirin dose. $\mathcal{F}$ Natl Cancer Inst 1997;89: $1152-60$.

32 Marnett LJ. Aspirin and the potential role of prostaglandins in colon cancer. Cancer Res 1992;52:5575-89.

33 Ferranoni M, La Vecchia C, D'Avanzo B, et al. Selected micronutrient intake and the risk of colorectal cancer. $\mathrm{Br} \mathcal{F}$ Cancer 1994;70:1150-5.

34 Potter JD. Colorectal cancer: molecules and populations. $\mathcal{F}$ Natl Cancer Inst 1999;91:916-32.

35 Feinberg AP, Vogelstein B. Hypomethylation of ras oncogenes in primary human cancers. Biochem Biophys Res Comm 1983;111:47-54

36 Chen J, Giovannucci E, Kelsey K, et al. A methylenetetrahydrofolate reductase polymorphism and the risk of colorectal cancer. Cancer Res 1996;56:4862-4.

37 Chen J, Giovannucci E, Hankinson SE, et al. A prospective study of methylenetetrahydrofolate reductase and methionine synthase gene polymorphisms, and risk of colorectal adenoma. Carcinogenesis 1998;19:2129-32.

38 Giovannucci E, Stampfer MJ, Colditz GA, et al. Multivitamin use, folate, and colon cancer in women in the Nurses' Health Study. Ann Intern Med 1998;129:517-24.

39 Hansen LA, Sigman CC, Andreola F, et al. Retinoids in and differentiation therapy. Carcinogenesis 2000;21:1271-9.

40 Huang ME, Ye YC, Chen SR, et al. Use of all-trans retinoic acid in the treatment of acute promyelocytic leukaemia.

41 Moon TE, Levine N, Cartmel B, et al. Effect of retinol in preventing squamous cell skin cancer in moderate-risk preventing squamous cell skin cancer in moderate-risk Epidemiol Biomarkers Prev 1997;6:949-56.

42 Hong WK, Lippman SM, Itri LM, et al. Prevention of second primary tumors with isotretinoin in squamous-cell carcinoma of the head and neck. N Engl f Med 1990;323:795801 .

43 Pastorino U, Infante M, Maioli M, et al. Adjuvant treatment of stage I lung cancer with high-dose vitamin A. $\mathcal{F}$ Clin Oncol 1993;11:1216-22.

44 Veronesi U, de Palo G, Marubini E, et al. Randomised trial of fenretinide to prevent second breast malignancy in women with early breast cancer. F Natl Cancer Inst 1999;91: $1847-56$.

45 Lever AF, Hole DJ, Gillis CR, et al. Do inhibitors of angiotensin-I-converting enzyme protect against the risk of cancer? Lancet 1998;352:179-84.

46 Folkman J. Clinical applications of research on angiogenesis. N Engl f Med 1995;333:1757-63.

47 Gately S, Twardowski P, Stack MS, et al. The mechanisms of cancer mediated conversion of plasminogen to the angiogenesis inhibitor angiostatin. Proc Natl Acad Sci US A 1997;94:10868-72.

48 Volpert OV, Ward WF, Lingen MW, et al. Captopril inhibits angiogenesis and slows the growth of experimental tumors in rats. F Clin Invest 1996;98:671-9.

49 Gescher AJ, Sharma RA, Steward WP. Cancer chemoprevention by dietary constituents: a salutary tale of failure and promise. Lancet Oncol 2001 (in press).

50 Cheng Al, Lin JK, Hsu MM, et al. Phase I chemoprevention clinical trial of curcumin (abstract). Tumor Biology 1998; 558a.

51 Plummer SM, Holloway KA, Manson MM, et al. Inhibition of cyclooxygenase 2 expression in colon cells by the chemopreventive agent curcumin involves inhibition of NF-kB activation via the NIK/IKK signalling complex. Oncogene 1999;18:6013-20.

52 Yin M-J, Yamamoto Y, Gaynor RB. The anti-inflammatory agents aspirin and salicylate inhibit the activity of IkB kinase- $\beta$. Nature 1998;396:77-80.

53 Rao CV, Rivenson A, Simi B, et al. Chemoprevention of colon carcinogenesis by dietary curcumin, a naturally occurring plant phenolic compound. Cancer Res 1995;55: 259-66.

54 Arbiser JL, Klauber N, Rohan R, et al. Curcumin is an in vivo inhibitor of angiogenesis. Mol Med 1998;4:376-83.

55 Kelloff JG, Crowell JA, Hawk ET, et al. Strategy and planning for chemopreventive drug development: clinical development plans II. $\mathcal{F}$ Cell Biochem 1996;26S:54-71.

56 Manson MM, Gescher A, Hudson EA, et al. Blocking and suppressing mechanisms of chemoprevention by dietary suppressing mechanisms of chemoprevention

57 Fearon ER, Vogelstein B. A genetic model for colorectal tumorigenesis. Cell 1990;61:759-67.

58 Forni G, Lollini PL, Musiani P, et al. Immunoprevention of cancer: is the time ripe? Cancer Res 2000;60:2571-5.

99 De Flora S, Balansky R, Scatolini L, et al. Adducts to nuclear DNA and mitochondrial DNA as biomarkers in chemoprevention. In: Stewart BW, McGregor D, Kleihues $\mathrm{P}$, eds. Principles of chemoprevention. IARC Scientific Publications No 139, 1996: 291-301.

60 Sharma RA. Cancer chemoprevention: a clinical reality. $f \mathcal{R}$ Soc Med 2000;93:518-20. 